\title{
Pressure dependent aerosol formation from the cyclohexene gas-phase ozonolysis in the presence and absence of sulfur dioxide: a new perspective on the stabilisation of the initial clusters $\dagger$
}

\author{
Philip Thomas Michael Carlsson, Janina Elisabeth Dege, Claudia Keunecke, \\ Bastian Christopher Krüger, Jan Lennard Wolf and Thomas Zeuch*
}

Received 6th March 2012, Accepted 18th June 2012

DOI: $10.1039 / \mathrm{c} 2 \mathrm{cp} 40714 \mathrm{k}$

The ozonolysis of cyclohexene is studied with respect to the pressure dependent formation of stable gas-phase products and secondary organic aerosol (SOA) as well as the influence of the presence of $\mathrm{SO}_{2}$. In addition the rate coefficient for the initial reaction cyclohexene $+\mathrm{O}_{3}$ was determined at $295 \mathrm{~K}$. The observed increase in CO and ethene yields at low pressures and the absence of ketene in the product spectrum confirm previously proposed reaction pathways forming these decomposition products. An enhanced ethene formation at pressures below 300 mbar coincides with drastically decreased aerosol yields pointing to a high influence on SOA formation of chemical activation driven dynamics in the vinylhydroperoxide channel. The static reactor experiments at 450 mbar in the presence of $\mathrm{SO}_{2}$ in the present study showed a similar sensitivity of additional particle formation to $\mathrm{H}_{2} \mathrm{SO}_{4}$ number densities as found in nearatmospheric flow reactor experiments [Sipilä et al., Science, 2010, 327, 1243], a surprising result with regard to the very different experimental approaches. At low pressures (around 40 mbar) no significant new particle formation is observed even at high $\mathrm{H}_{2} \mathrm{SO}_{4}$ concentrations. These findings indicate that the collisional stabilisation of initial clusters is an important aspect for SOA formation processes involving sulfuric acid and organic compounds. The results may have implications for geo-engineering strategies based on stratospheric sulfur injection, but caution is mandatory when room temperature laboratory results are extrapolated to stratospheric conditions.

\section{Introduction}

Both mass balances of atmospheric aerosol and aerosol particle numbers are key issues in atmospheric science, since they are closely related to crucial processes like cloud formation ${ }^{1,2}$ and potential health effects of particles. Unravelling the underlying chemistry and physics at a molecular level is the ultimate goal for better understanding complex phenomena such as the extent of human influence on climate change patterns. Sulfuric acid $\left(\mathrm{H}_{2} \mathrm{SO}_{4}\right)$ initiated new particle formation has been demonstrated in laboratory experiments to be able to account for nucleation events under ambient atmospheric concentrations. ${ }^{3,4}$ The atmospheric growth of newly formed particles involves oxidation products of bio- and anthropogenic volatile organic compounds leading to the formation of secondary organic aerosol (SOA). Very recently, it was shown that at

Georg-August-Universität Göttingen, Institut für Physikalische

Chemie, Tammannstraße 6, 37077 Göttingen, Germany.

E-mail: tzeuch1@gwdg.de

$\dagger$ Electronic supplementary information (ESI) available. See DOI: $10.1039 / \mathrm{c} 2 \mathrm{cp} 40714 \mathrm{k}$ least half of the observed particle growth rate in the 2-20 nm size range can be explained by condensation of products being produced from gas-phase chemistry. ${ }^{5}$ However, the compounds controlling the stabilisation of the initial sulfuric acid clusters and their growth have not been well characterised so far, although recently significant progress has been made., ${ }^{4,6}$ Stable products of low volatility as well as intermediate species like Criegee Intermediates (CIs) being produced during the oxidation of terpenes by ozone are considered to be involved. ${ }^{7,8}$ The ozonolysis of unsaturated hydrocarbons in the atmosphere is a major source of oxidation products with very low vapour pressures. ${ }^{7,9,10}$ In recent studies we could show that SOA formation from cyclic alkene ozonolysis is highly dependent on the transient chemistry. ${ }^{11,12}$ Hence, the processing of chemical activation through the reaction pathways is crucial ${ }^{13}$ and it turned out that pressure is a key parameter controlling the stoichiometric yield of condensable species. ${ }^{12}$

The ozonolysis of cyclohexene (CHEX) is an important model system for the atmospheric oxidation of alkenes since it shows the basic structural unit of the abundant biogenic terpene, $\alpha$-pinene. Thus the gas-phase ozonolysis mechanism 
and SOA formation from this reaction was studied extensively in the past. ${ }^{14-19}$ However, the effect of pressure variation has received less attention.

By addition of $\mathrm{SO}_{2}$ to the initial reaction mixture, $\mathrm{H}_{2} \mathrm{SO}_{4}$ is formed in the presence of water mainly in a reaction sequence starting with the reaction $\mathrm{SO}_{2}+\mathrm{OH} \rightarrow \mathrm{HOSO}_{2},{ }^{20}$ where the $\mathrm{OH}$ radicals are formed during the alkene ozonolysis. ${ }^{21,22}$ In this reaction system organic and sulfuric acid based chemistry run in parallel and therefore it lends itself well to examine their effect on SOA formation. This idea was extensively exploited by Berndt et al. with sulfuric acid chemistry controlling nucleation in flow reactor experiments focussing on nearatmospheric conditions. ${ }^{20,23}$

In laboratory studies often much higher alkene conversions are used. ${ }^{19,24}$ Here, the situation may change and the role of cross reactions between sulfuric acid and organic compounds is potentially elucidated. Since pressure affects the stability and lifetimes of intermediate species and freshly formed clusters its variation may reveal crucial pieces of information about the stability of the initial clusters during new particle formation. These considerations lead to the goals of the present study. In a first step we have studied the reaction kinetics, product and SOA formation during CHEX ozonolysis focussing on the effect of pressure. In the second step we have explored how sulfur and organic chemistry interact in the context of particle formation in experiments in the presence of $\mathrm{SO}_{2}$ under different pressures.

\section{Experimental section}

The apparatus and the conduction of experiments have been described in detail elsewhere. ${ }^{12}$ Therefore only a description of the main features is given here. All ozonolysis experiments were performed in a static reaction chamber with a volume of $64 \mathrm{~L}$. In the preparation run of each experiment the aerosol cell was passivated by filling with $1000 \mathrm{ppm}$ ozone for 10 minutes and flushed several times (4-5). Reactant gases were first filled in two premixing chambers of $40 \mathrm{~L}$ volume. One of them was used as ozone reservoir and equipped with UV optics for a continuous measurement of $\mathrm{O}_{3}$ concentrations. The ozone chamber and the reaction cell have Teflon coated walls. Ozone was produced by using a commercial ozone generator (Sander 301.7) and stored at low temperature (cold trap, $220 \mathrm{~K}$ ) by adsorption on silica beads in quartz bottles. Concentrations of reactants (alkenes, ozone) and the main reaction products and their yields were determined using infra-red spectroscopy (Bruker IFS 66, $12 \mathrm{~m}$ path length in the cell). Standard volumetric procedures were used for calibrations.

Special attention was given to the $\mathrm{SO}_{2}$ concentrations. First, the infrared detection of $\mathrm{SO}_{2}$ was calibrated by analysing mixtures of $\mathrm{SO}_{2}$ with nitrogen and synthetic air by IR-spectroscopy. This procedure provided apparatus- and band-specific absorption coefficients for different pressures (30, 100, 500, and 1000 mbar). Similar procedures were previously applied in our lab in studies, where $\mathrm{SO}_{2}$ was used as a photolytic source of $\mathrm{O}$ atoms. ${ }^{25,26}$ For the particle formation experiments at a partial pressure of $50 \mathrm{~Pa} \mathrm{SO}_{2}$ was filled into $2 \mathrm{~L}$ and $10 \mathrm{~L}$ glas flasks, which were then filled with nitrogen at a pressure of 1 bar.
The actual $\mathrm{SO}_{2}$ concentration in the glas flask was analysed at the beginning of a series of experiments by IR-spectroscopy. With the known dilution in the flask the $\mathrm{SO}_{2}$ concentrations in the experiments could be derived volumetrically. $\mathrm{H}_{2} \mathrm{SO}_{4}$ is formed in the reaction sequence:

$$
\begin{gathered}
\mathrm{SO}_{2}+\mathrm{OH} \rightarrow \mathrm{OHSO}_{2} \\
\mathrm{OHSO}_{2}+\mathrm{O}_{2} \rightarrow \mathrm{HO}_{2}+\mathrm{SO}_{3} \\
\mathrm{SO}_{3}+\mathrm{H}_{2} \mathrm{O} \rightarrow \mathrm{H}_{2} \mathrm{SO}_{4}
\end{gathered}
$$

$\mathrm{OH}$ radicals are produced during cyclohexene ozonolysis with a yield of $Y_{\mathrm{OH}}$ of $c a$. 0.50 (see next section). From the $\mathrm{SO}_{2}$ concentration and the $\mathrm{OH}$ yield of the CHEX ozonolysis $\mathrm{H}_{2} \mathrm{SO}_{4}$ concentrations can be simulated by kinetic modeling, which is a standard approach ${ }^{4,6,20}$ and well established in our group. ${ }^{11,27}$ Additional formation of $\mathrm{SO}_{3}$ via $\mathrm{CI}+\mathrm{SO}_{2}$ is assumed to be negligible due to the absence of stabilised CI's during CHEX ozonolysis. ${ }^{13}$ In general this additional source of $\mathrm{H}_{2} \mathrm{SO}_{4}$ must be considered for alkene ozonolysis experiments in the presence of $\mathrm{SO}_{2} \cdot{ }^{20,51}$ Particle classifiers (TSI SMPS 3936 with NDMA (3085) and LDMA (3081) as well as a 3022 CPC (condensation particle counter)) were used for particle measurements (operation parameters: 2 litres per minute (lpm) sheath flow and $0.2 \mathrm{lpm}$ sample flow). Aerosol mass yields were estimated from the size distribution assuming spherical particles and a density of $1.2 \mathrm{~g} \mathrm{~cm}^{-3}$.

The pressure variation in the aerosol chamber was achieved as follows. First, the premixing chambers were filled with the reactants. Then they were filled with bath gas (synthetic air or nitrogen) up to pressures between 50 and 1000 mbar. Additional substances like sulfur dioxide or the $\mathrm{OH}$ scavenger cyclohexane were either added to the premixing chamber or the evacuated aerosol chamber. The valves to the aerosol chamber were opened for $3 \mathrm{~s}$ for starting the ozonolysis. Within $3 \mathrm{~s}$ the initial pressure difference is relaxed by $c a .80 \%$ and a backflow of gas to the premixing chambers is avoided. The resulting pressures were between 20 and 450 mbar. For experiments at higher pressures the desired amount of bath gas is added after the expansion, which takes less than $15 \mathrm{~s}$ for 1000 mbar. The fast filling and mixing of the gases minimized the time period at inhomogeneous reactant concentrations and an undefined reaction pressure. In consequence more than $95 \%$, typically $99 \%$, of the ozone was consumed at a defined pressure due to the short mixing time.

After more than $95 \%$ of ozone had been consumed at the chosen reaction pressure the reaction cell was filled to 1 bar with synthetic air. The fast reactant consumption allows the time separation of gas-phase kinetics and aerosol formation at various pressures from aerosol classification being restricted to 1 bar. The temperature was held constant at $(295 \pm 0.5) \mathrm{K}$ during all experiments. To this end, the laboratory was airconditioned and the aerosol cell was thermalized by a temperature control circuit. Here its double-shell construction allows for thermalizing the inner wall.

Commercially available chemicals were used without further purification, see Table 1 . 
Table 1 Chemicals

\begin{tabular}{lll}
\hline Substance & Purity (\%) & Manufacturer \\
\hline Synthetic air $\left(\mathrm{N}_{2} / \mathrm{O}_{2}: 79.5 / 20.5\right)$ & $\geq 99.9990$ & Air Liquide \\
Nitrogen & $\geq 99.9990$ & Air Liquide \\
Oxygen & $\geq 99.995$ & Air Liquide \\
Helium & $\geq 99.996$ & Air Liquide \\
Cyclohexane & $\geq 99.5$ & Merck \\
Cyclohexene & $\geq 99.7$ & Fluka \\
Sulfur dioxide & $\geq 99.98$ & Messer \\
Demineralised water & - & - \\
\hline
\end{tabular}

\section{Results and discussion}

\subsection{Kinetics}

First, we will present and discuss our results on the elementary kinetics of the reaction $\mathrm{CHEX}+\mathrm{O}_{3}$. The procedure for deriving the rate coefficient $k$ from online measurements of the concentrations of $\mathrm{O}_{3}$ and the alkene is identical with our recent study. ${ }^{12}$ The design of the experimental arrangement allows the fast preparation of a homogeneous reaction mixture in terms of initial reactant concentrations and pressure. Choosing initial alkene and ozone concentrations such that around $80 \%$ of ozone is consumed within the first 5 minutes the reactant concentrations can be monitored simultaneously by IR-spectroscopy. By averaging IR-spectra at intervals of 32 s ozone and CHEX concentration-time profiles were generated, which provide a sensitive measure for the alkene $+\mathrm{O}_{3}$ rate coefficient. One important aspect of the ozonolysis of alkenes is the release of $\mathrm{OH}$ radicals from the decomposition of CIs, which in turn react with the double bond of the alkene. $^{21,22,28-31}$ Therefore many studies on kinetics, product or SOA formation from alkene ozonolysis employ $\mathrm{OH}$ radical scavengers like cyclohexane, butanol or carbon monoxide to reduce contributions originating from the $\mathrm{OH}$ chemistry. ${ }^{32} \mathrm{How}-$ ever, the pool of peroxy radicals $\left(\mathrm{RO}_{2}\right)$ and the critical $\mathrm{HO}_{2} / \mathrm{RO}_{2}$ concentration ratio are influenced by $\mathrm{OH}$ scavenger addition, which may cause other unwanted side effects. ${ }^{33}$ In the absence of an $\mathrm{OH}$ scavenger the additional alkene consumption by $\mathrm{OH}$ must be accounted for in the determination of the rate coefficient. In the present study this is achieved by measuring the yield of $\mathrm{OH}$ $\left(Y_{\mathrm{OH}}\right)$ using the approach of Neeb and Moortgat. ${ }^{29}$ The general overall ozonolysis reaction is treated as

$$
\nu_{\mathrm{Oz}} \mathrm{O}_{3}+\nu_{\mathrm{Al}} \mathrm{CHEX} \stackrel{k}{\rightarrow} \text { products }
$$

While assuming $\nu_{\mathrm{Oz}} \approx 1$ by neglecting the influence of $\mathrm{HO}_{2}$ radicals (see discussion in Wolf et al. ${ }^{12}$ ) the stoichiometric coefficient for the alkene should be composed of $\nu_{\mathrm{Al}}=1+Y_{\mathrm{OH}}$. By measuring the alkene conversion relative to the ozone conversion, the yield $Y_{\mathrm{OH}}$ of $\mathrm{OH}$ radicals can be derived as

$$
\begin{gathered}
Y_{\mathrm{OH}}=\nu_{\mathrm{Al}}-1 \\
\approx \frac{\Delta p(\mathrm{CHEX})}{\Delta p\left(\mathrm{O}_{3}\right)}-1
\end{gathered}
$$

Accounting for the additional $\mathrm{OH}$ initiated alkene consumption the integrated second order time law reads:

$$
\frac{1}{\nu_{\mathrm{Al}} \cdot p_{0}\left(\mathrm{O}_{3}\right)+p_{0}(\mathrm{CHEX})} \cdot \ln \left(\frac{p_{0}\left(\mathrm{O}_{3}\right) \cdot p(\mathrm{CHEX})}{p\left(\mathrm{O}_{3}\right) \cdot p_{0}(\mathrm{CHEX})}\right)=k t
$$

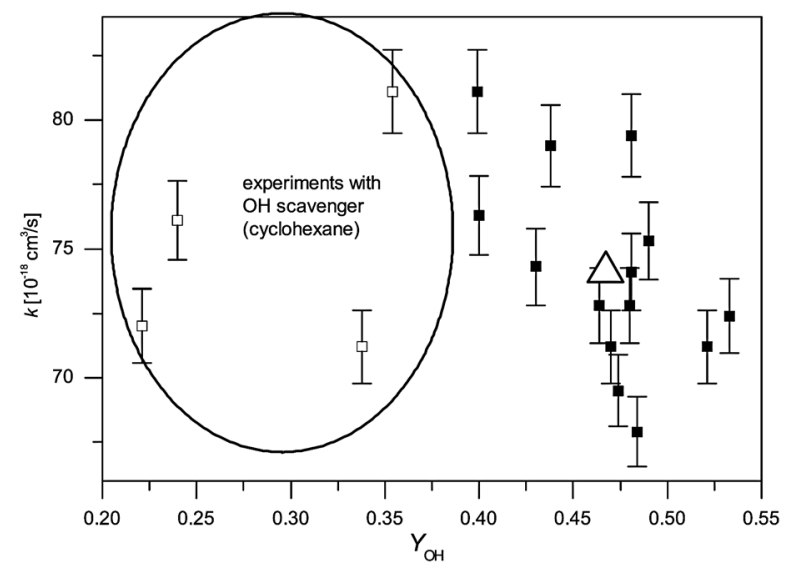

Fig. 1 Derived ozonolysis rate constants at $(295 \pm 0.5) \mathrm{K}$ versus the measured $\mathrm{OH}$ yields $\left(Y_{\mathrm{OH}}=\frac{\Delta p\left(\mathrm{C}_{6} \mathrm{H}_{10}\right)}{\Delta p\left(\mathrm{O}_{3}\right)}-1\right)$. Four encircled experiments were carried out in the presence of cyclohexane to scavenge at least some part of the $\mathrm{OH}$ radicals additionally reacting with the alkene. The hollowed triangle denotes the center of gravity of all experiments without an $\mathrm{OH}$ scavenger.

Thus the bimolecular rate coefficient $k$ of the ozone reaction can be obtained from the concentration (or equivalently partial pressure) time profiles of both reactants when the left hand side of eqn (4) is plotted versus the time. ${ }^{12}$

Rate coefficients $k$ and $\mathrm{OH}$ yields $Y_{\mathrm{OH}}$ have been determined in a series of experiments at pressures between 25 and 1000 mbar along the procedure outlined above. The initial partial pressures ranged from $0.17-0.55 \mathrm{~Pa}$ (1.7 to $5.5 \mathrm{ppm}$ at 1 bar) for ozone and from $0.43-0.93 \mathrm{~Pa}$ (4.3 to $9.3 \mathrm{ppm}$ at $1 \mathrm{bar}$ ) for CHEX. Neither the variation in pressure nor the variation in initial alkene and $\mathrm{O}_{3}$ concentrations showed an obvious impact on the determined $k$ values. This is illustrated in Fig. 1 where $k$ is plotted against the corresponding $\mathrm{OH}$ yields. Both show only a slight scatter with $k$ ranging from (67-81) $10^{-18} \mathrm{~cm}^{3} \mathrm{~s}^{-1}$ and $Y_{\mathrm{OH}}$ ranging from 0.4 to 0.53 . The open triangle is the centre of gravity and marks the resulting averaged values. The rate coefficient $k$ is within the error range of several previous studies ${ }^{34-36}$ and virtually identical with the report of Treacy and co-workers. ${ }^{34} Y_{\mathrm{OH}}$ is slightly lower than the reported values based on different experimental methods, ${ }^{14,17,30}$ but within the limit of the reported error margins (see Table 2). We did not observe a pressure dependence of the $\mathrm{OH}$ yields, which is similiar to the results of Fenske et al. for $\mathrm{C}_{3}$ - and larger alkenes including cyclopentene. ${ }^{30}$

In several experiments the presence of cyclohexane (20-30 Pa) as $\mathrm{OH}$ scavenger was examined. The results are depicted by the

Table 2 Comparison of calculated $Y_{\mathrm{OH}}$ and $k$ values with data from the literature. The given error of our data is calculated from statistical methods only ( $95 \%$ confidence interval). A more appropriate accuracy including uncertainties in concentration calibration should be in the order of twice these values

\begin{tabular}{llll}
\hline$Y_{\mathrm{OH}}$ & Ref. & $K / 10^{-18} \mathrm{~cm}^{3} \mathrm{~s}^{-1}$ & Ref. \\
\hline $0.47 \pm 0.02$ & This work & $74 \pm 2(295 \mathrm{~K} \pm 0.5 \mathrm{~K})$ & This work \\
$0.54 \pm 0.08$ & 17 & $85 \pm 8(298 \mathrm{~K})$ & 34 \\
$0.54 \pm 0.13$ & 30 & $81(298 \mathrm{~K})$ & 35 \\
$0.52^{a}$ & 14 & $76(293 \mathrm{~K})$ & 35
\end{tabular}

${ }^{a}$ This value is calculated from the relative ozone consumption $(0.66)$ according to eqn (3). 
open circles in Fig. 1. As an effect of $\mathrm{OH}$ scavenging, $Y_{\mathrm{OH}}$ is reduced in these experiments but still well above 0 . Using higher cyclohexane concentrations would hamper the integration of IR-bands by spectral interference. Similar to the preceding study we did not find an effect of scavenger addition on the determined $k$ values. This observation gives us further confidence that our straight forward analysis provides reliable results for $k$ and $Y_{\mathrm{OH}}$, which is reflected by the good agreement with literature values for CHEX $+\mathrm{O}_{3}$ and several other cyclic alkenes in our previous work. ${ }^{12}$ Fortunately, as partly discussed above, the well defined starting point of the alkeneozone reaction due to the fast initial mixing allows the use of rather large initial concentrations and the measurement of reactant consumption in the initial phase of reaction, which seems to be a robust measure for $k$. If a more accurate determination of $k$ is desired, not only the reactants but also $\mathrm{OH}$ and $\mathrm{HO}_{2}$ radicals have to be monitored simultaneously. Such experiments can provide the important $\mathrm{OH}$ and $\mathrm{HO}_{2}$ yields on the basis of in situ measurements. ${ }^{37}$ Then the systematic error, which is caused from $\mathrm{O}_{3}$ consumption by $\mathrm{HO}_{2}$, can be controlled as discussed recently. ${ }^{12}$

\subsection{Gas-phase products}

The following analysis of pressure dependent product formation from CHEX $+\mathrm{O}_{3}$ takes up our recent findings for methyl-cyclohexene $(\mathrm{MCHe})$ and $\alpha$-pinene. For these alkenes the formation of $\mathrm{CO}$ was significantly increased at lower pressures, indicating that channels different from CI decomposition must contribute to the observed $\mathrm{CO}$ yields. A second important finding was the observation of ethene and ketene formation for MCHe in the low pressure regime ( $p<100 \mathrm{mbar}$ ); for $\alpha$-pinene only ketene was detected at low pressures. These findings were interpreted such that chemically activated alkyl radicals being formed after $\mathrm{OH}$ elimination in the vinylhydroperoxide channel decompose at low pressure, which is similar to the reaction mechanism of chemically activated cylic-alkoxy radicals. ${ }^{26,38}$ The absence of ethene formation in the case of $\alpha$-pinene was explained with the internal ring, which inhibits a second $\mathrm{C}-\mathrm{C}$-fission. The analogous mechanisms for the reactions of CHEX, MCHe and $\alpha$-pinene with ozone are illustrated in Fig. 2. If the mechanism proposed in ref. 11 was correct, ketene formation should not be observed for CHEX $+\mathrm{O}_{3}$ due to the absence of di-substituted CIs (pathway (b) in Fig. 2). Instead an increased CO formation is expected, since only pathway (a) is available.

The ozonolysis of CHEX clearly provides a critical test for these hypotheses. Therefore the pressure dependent product formation is extensively analysed with focus on the decomposition pathways depicted in Fig. 2. In addition formic acid, which is known to be formed from an additional source on a much longer timescale, ${ }^{17}$ is included in the product analysis.

The differences in product formation at high and low pressures are illustrated in Fig. 3. The product spectra were recorded for nearly identical ozone conversions $\left(\Delta p\left(\mathrm{O}_{3}\right)=\right.$ $0.90 \mathrm{~Pa})$ at 990 and $46 \mathrm{mbar}$, corrected for remaining reactant specific bands by subtracting pure substance spectra. Some prominent, qualitative changes in the formation of stable gas-phase products between the two pressure levels can be

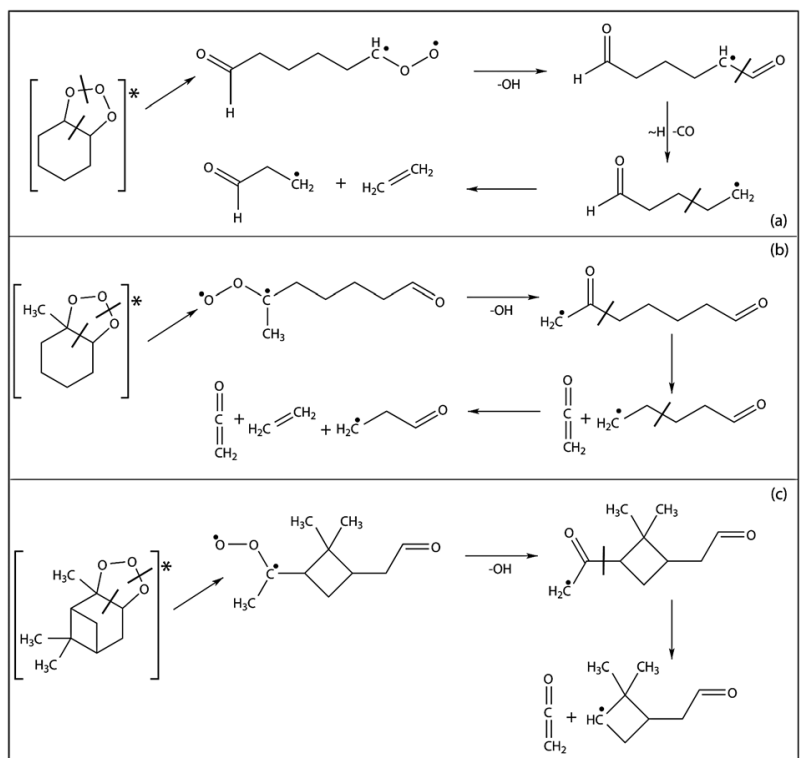

Fig. 2 Possible formation pathways of ketene, ethene and $\mathrm{CO}$ at lower pressures. (a) $\mathrm{CO}$ and ethene formation from the monosubstituted CI (CHEX, MCHe); (b) ketene and ethene formation from the di-substituted $\mathrm{CI}(\mathrm{MCHe})$; (c) ketene formation and inhibited ethene formation from the di-substituted CI ( $\alpha$-pinene).

observed. These are increased yields with decreasing pressure of carbon monoxide ( $\mathrm{CO}$, rotationally resolved $\mathrm{P}-\mathrm{R}$ bandshape around $\left.2150 \mathrm{~cm}^{-1}\right)$, ethene $\left(\mathrm{C}_{2} \mathrm{H}_{4}\right.$, the sharp Q-branch at $\left.950 \mathrm{~cm}^{-1}\right)$ and formic acid ( $\mathrm{HCOOH}, \mathrm{P}-\mathrm{Q}-\mathrm{R}$ bandshape at 1105 and $1776 \mathrm{~cm}^{-1}$ ) as well as the formation of small amounts of formaldehyde (HCHO, Q-branch at $1745 \mathrm{~cm}^{-1}$ ), which cannot be detected at atmospheric pressure. ${ }^{14,17,39}$ Additionally, a decrease of absorption bands for example in the carbonyl stretching region from products such as pentanal appears. ${ }^{26}$ The formation of ketene was neither observed at 990 nor at 46 mbar.

The elevated formation of small fragment molecules (1-2 carbon atoms) instead of longchain products (5-6 carbon atoms, for example pentanal) leads to a reduction of the total sum of vibrational modes based on the $3 N-6$ rule for nonlinear molecules. Therefore, in general, the integral of all bands of the reaction products is lowered (assuming similar transition dipole moments of vibrational excitations for both types of molecules). Due to the applied moderate spectral resolution of $1 \mathrm{~cm}^{-1}$ the decreased pressure broadening of absorption bands at low pressures (around 50 mbar) only slightly affects the line shape in most cases, except for CO. ${ }^{12}$ Therefore we used calibrated pure substance spectra being recorded over a range of total pressures between 20 and 1000 mbar for the determination of $\mathrm{CO}$ yields.

During each experiment, a series of nine spectra was recorded within a period of 12 minutes, showing the consumption of reactants and the formation of stable products at specific absorption bands as described above. By subtracting pure substance spectra, the actual concentration of identified products as well as the concentration of remaining reactants can be determined at each reaction time (the midst of the time interval needed for recording the spectrum). By comparing the 

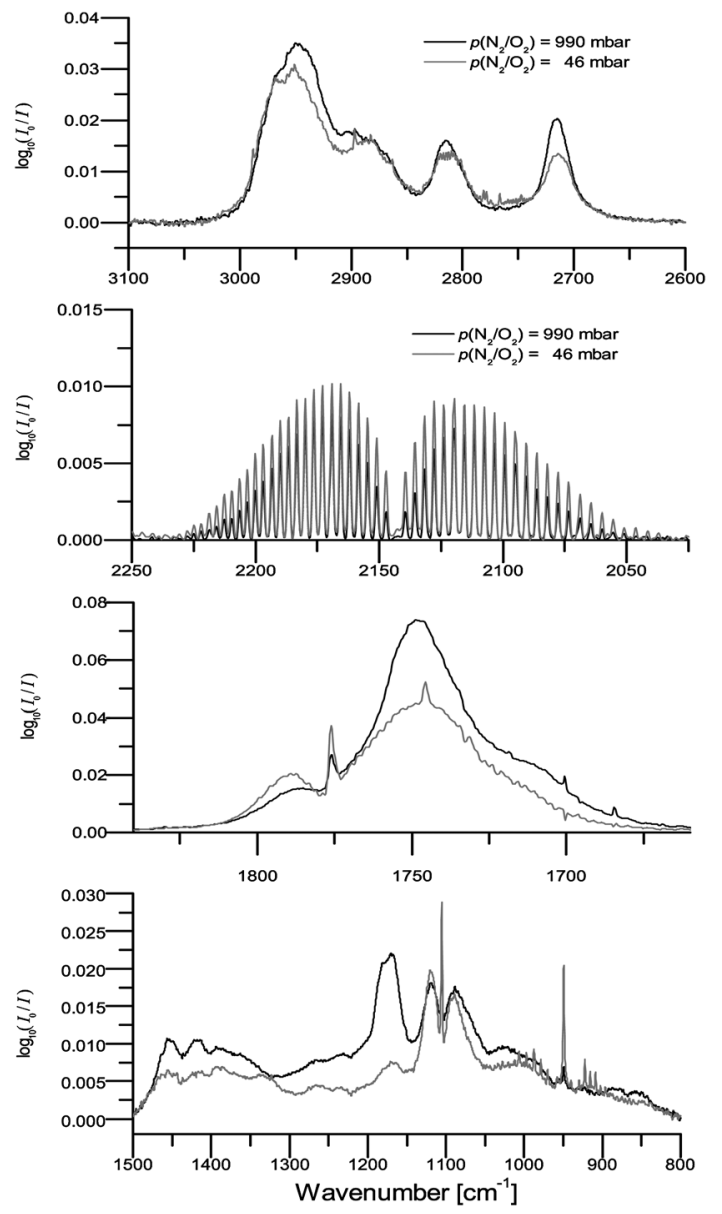

Fig. 3 Product spectra of cyclohexene ozonolysis at identical ozone conversions $(0.9 \mathrm{~Pa})$ for atmospheric pressure and low pressure of synthetic air. Upper panel: $\mathrm{C}-\mathrm{H}$ stretching region; middle panels: $\mathrm{C}=\mathrm{O}$ and carbonyl stretching region; lower panel: fingerprint region.

partial pressure of products $p_{\mathrm{CO}}, p_{\mathrm{HCOOH}}$, and $p_{\mathrm{C}_{2} \mathrm{H}_{4}}$ with the ozone consumption $-\Delta p_{\mathrm{O}_{3}}=p_{\mathrm{O}_{3}}(t=0)-p_{\mathrm{O}_{3}}(t)$ the relative formation yields $Y_{\mathrm{CO}}, Y_{\mathrm{HCOOH}}$, and $Y_{\mathrm{C}_{2} \mathrm{H}_{4}}$ can be calculated. Fig. 4 shows these data for a selection of different pressures. All three decomposition products are obviously produced with higher yields at lower pressures. Ethene and carbon monoxide (higher pressures) show a formation strictly proportional to reactant conversion as expected. The deviation for carbon monoxide at the lowest pressure and highest conversion shows the necessity for the tedious procedure of generating conversion and pressure specific calibration spectra. Such a deviation immediately results at low pressure when extrapolated calibration spectra are applied as exemplified here. The left curved deviation, however, observed for $\mathrm{HCOOH}$ was previously reported ${ }^{17}$ and can be attributed to the known delayed formic acid formation. Hence only initial yields were determined for $\mathrm{HCCOH}$. Especially for the lowest pressure the initial yields differ significantly from yields that are determined from a best linear fit (see the lower panel of Fig. 4). We note that for the conditions of our experiment the formation of $\mathrm{HCOOH}$ from the side reaction ethene $+\mathrm{O}_{3}$ can be excluded based on its much lower reaction rate (CHEX is in excess over $\mathrm{O}_{3}$ ). We further note that for high ozone conversions the reaction rate
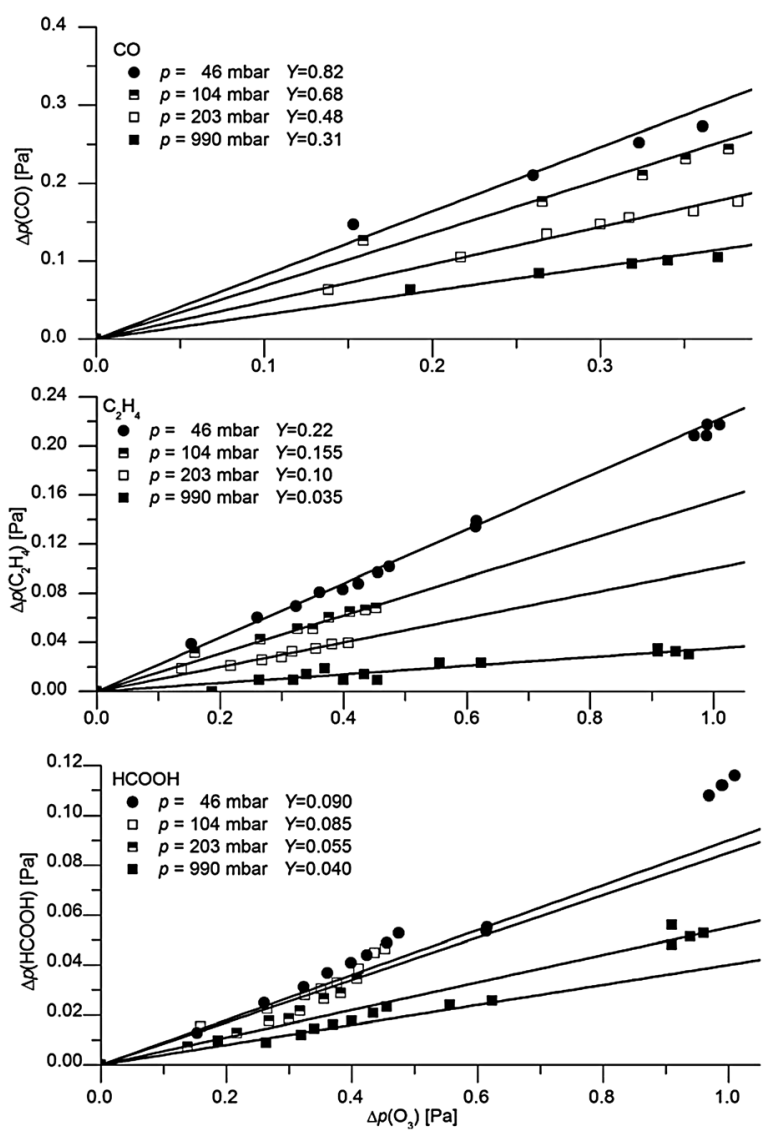

Fig. 4 Representative determination of product yields for $\mathrm{CO}, \mathrm{C}_{2} \mathrm{H}_{4}$ and $\mathrm{HCOOH}$ relative to ozone conversion. For the sake of clarity not all performed experiments are shown. In the case of $\mathrm{HCOOH}$ only initial yields were obtained due to the secondary origin of the reaction product at longer reaction times.

is decreased and a reliable determination of the relatively low ozone concentrations is more difficult. However, under these conditions the delayed formation of additional $\mathrm{HCOOH}$ is most pronounced as shown in Fig. 4 for the lowest and highest pressures.

The comparison of $\mathrm{CO}$ and ethene yields at high and low pressures from the CHEX ozonolysis with the results for $\mathrm{MCHe}$ and $\alpha$-pinene confirms the mechanism being proposed in ref. 11. First, the absence of ketene formation is in line with the absence of di-substituted CIs for CHEX ozonolysis. Second, the significantly increased CO yields for CHEX compared with $\mathrm{MCHe}$ (0.31-0.19 around 1000 mbar, $0.82-0.43$ around 45 mbar) agree with pathway (a) in Fig. 2 being the additional source besides CI decomposition. For $\mathrm{MCHe}$ this channel applies only for the mono-substituted CI, for CHEX a mono-substituted CI is solely formed. Third, the significantly increased ethene yields for CHEX ozonolysis indicate the crucial role of chemical activation of intermediates being formed in the vinylhydroperoxide channel. In the case of the CHEX ozonolysis the intermediates have a lower heat capacity and thus the chemical activation driven unimolecular reaction dynamcis are intensified. As a consequence ethene is observed as a product already for the ambient pressure case of CHEX, while it can be detected in our cell only below 200 mbar 
for $\mathrm{MCHe}$ for identical ozone conversions. We note that ethene formation at 1 bar was reported by Hatakeyama et al. in their early work. ${ }^{14}$ The mechanism being illustrated in Fig. 2 shows that $\mathrm{CO}$ and ethene are formed in succession. The first $\mathrm{C}-\mathrm{C}$-fission leads to $\mathrm{CO}$ and the second to ethene formation. Since the excess energy in the intermediate alkyl radicals is reduced by the first $\mathrm{C}-\mathrm{C}$ fission the product yields of $\mathrm{CO}$ and ethene are expected to show different pressure dependencies. And this is indeed observed in the pressure profiles of $\mathrm{CO}$ and ethene yields being shown in Fig. 5. While the CO formation approaches a low pressure limit below 100 mbar, ethene formation is enhanced below 300 mbar and no indication of reaching a low pressure limit is found. This observation is typical for products being formed at different stages in unimolecular reaction systems, where the initial excess energy is processed through the potential energy surface. This characteristic feature of the gas-phase alkene ozonolysis was recently discussed by Donahue at al. in a review article for the primary ozonide, the CI and the vinylhydroperoxide. ${ }^{13}$ The present study shows that the chemical activation is carried through beyond the vinylhyroperoxide in the case of CHEX ozonolysis. Enhanced formation of ethene from intermediate alkyl radicals is observed at low pressures because first, the preceding $\mathrm{C}-\mathrm{C}$-fission reduces their internal energy and

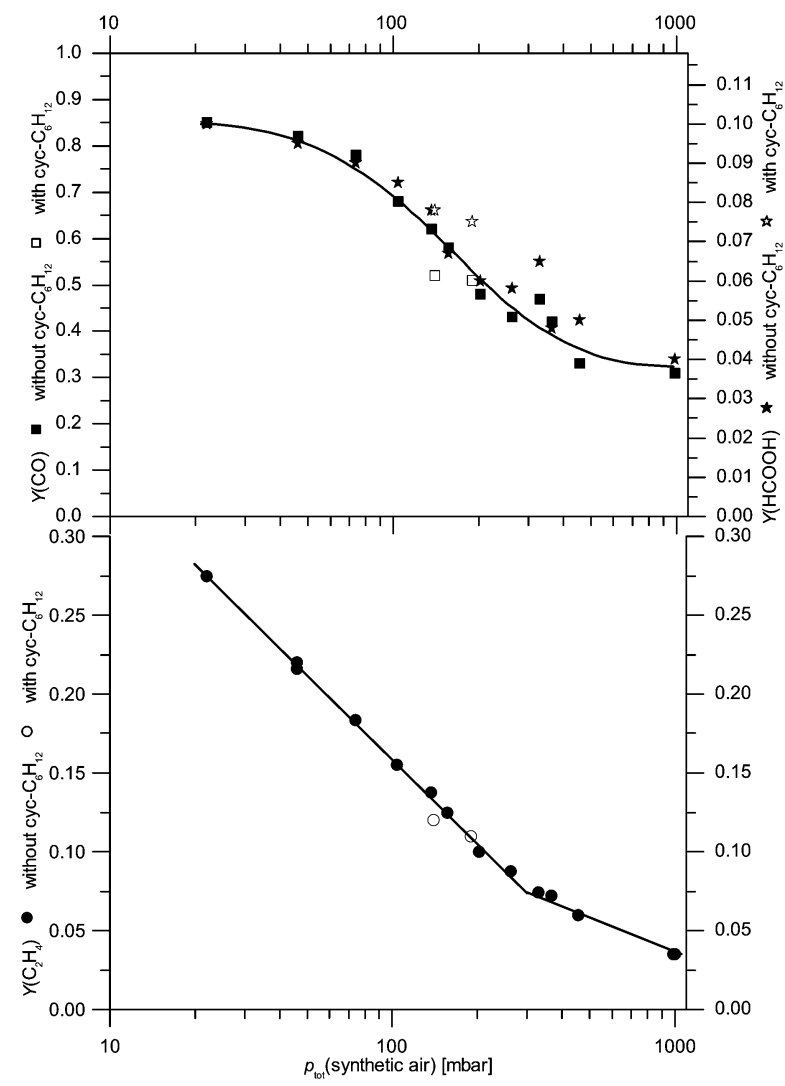

Fig. 5 Pressure profiles of decomposition product yields (upper panel: $\mathrm{CO}$ and $\mathrm{HCOOH}$, lower panel: $\mathrm{C}_{2} \mathrm{H}_{4}$ ). Open icons represent experiments with cyclohexane as an $\mathrm{OH}$ scavenger. The lines serve just to guide the eyes. Overall relative accuracy is in the order of $10-15 \%$, error bars are omitted for clarity. Please note the logarithmic scaling of the pressure axis as well as the different scaling for $\mathrm{HCOOH}$ (stars) and $\mathrm{CO}$ (squares, $10 \times$ higher) in the upper panel. second, they are formed later, which increases their chance for stabilisation by collisions with bath gas molecules. Interestingly, the initial $\mathrm{HCOOH}$ yields show pressure profiles similar to $\mathrm{CO}$ indicating their formation at an earlier stage than ethene.

The confirmation of the mechanism being proposed in ref. 11 is an important step for understanding the drastically reduced aerosol yields at low pressure reported for the ozonolysis of endo- and exocyclic alkenes in the same study. This issue is the content of the next section. We note that the mechanism as depicted in Fig. 2 needs further characterization by means of quantum chemistry for identifying the involved transition states. Efforts in this direction are on the way.

\subsection{SOA formation}

3.3.1 Absence of $\mathbf{S O}_{2}$. In the preceding work on particle formation during the ozonolysis of larger cyclic alkenes we could show that pressure is an important parameter which highly influences the stoichiometric yield of condensable species and the number of condensation nuclei being formed. ${ }^{12}$ In the present study the pressure effect on gas- to particle-phase partitioning of products from the alkene ozonolysis reaction was examined in more detail.

For the ozonolysis of CHEX we observed in general astonishingly low particle numbers of $c a .5000 \mathrm{~cm}^{-3}$ at $0.45-1$ bar and 1 ppm ozone conversion. Since significant amounts of condensable products were produced, the observed particles were comparatively large, which is illustrated in Fig. 6. The cut off of our DMA at $780 \mathrm{~nm}$ necessitated the simulation of the particle size distribution for obtaining a more realistic estimate of aerosol masses. The reported particle numbers and aerosol masses were in all cases derived by integrating the simulated particle size distribution. An example for the procedure is depicted in Fig. 6.

The dependence of particle formation on ozone conversion and reaction pressure was examined for four different pressures between 465 and 89 mbar and ozone conversions between 0.1 and $0.53 \mathrm{~Pa}$ ( 1 and $5.3 \mathrm{ppm}$ at 1 bar). The results are depicted in Fig. 7. We see that the slopes derived from linear regression increase for both particle number densities and

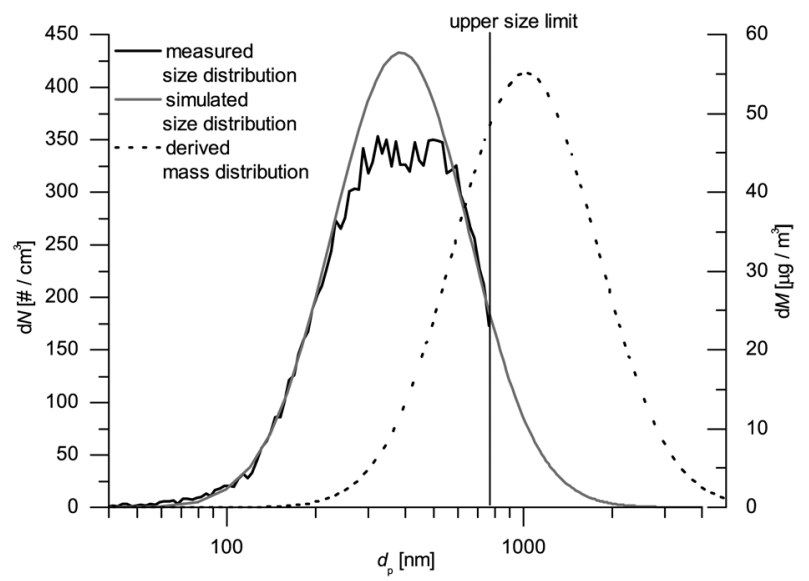

Fig. 6 Size (measured and simulated) and (derived) mass distribution of a cyclohexene ozonolysis $\left(\Delta p\left(\mathrm{O}_{3}\right)=0.44 \mathrm{~Pa}\right)$ at $316 \mathrm{mbar}$ synthetic air. Comparison between measured and simulated (in parantheses) key data: $N=13200$ (16000) \# per $\mathrm{cm}^{3}, d_{N}=360$ (385) nm, $M=750$ (2032) $\mu \mathrm{g} \mathrm{m}^{-3}, \sigma_{\mathrm{g}}=1.65$ (1.70). 
mass yields with increasing pressure. This illustrates that the amount of condensable products per reacted alkene is a sensitive function of the reaction pressure. The slopes being shown in Fig. 7 indicate a linear increase, which is expected when a critical alkene conversion is surpassed, ${ }^{40}$ suggesting that the procedure for estimating aerosol masses is reliable. The comparison of the slope for 180 mbar and 318 mbar is striking. In this small pressure window of about 140 mbar the yield of condensable reaction products increases for the same amount of reacted ozone by a factor of almost three. In Fig. 5 we see that ethene formation is intensified below $300 \mathrm{mbar}$. This finding indicates that the chemical activation of alkyl radicals producing ethene by $\mathrm{C}-\mathrm{C}$-fission (see Fig. 2) is critical for SOA formation. The reason may be that the excess energy reduces the lifetimes of peroxy radicals being formed by $\mathrm{O}_{2}$ addition to this intermediate. As a consequence they cannot take part in bimolecular gas-phase reactions producing chemically bonded dimers. ${ }^{24,41}$ The reason may also be that decomposition reactions are enhanced upon chemical activation, which increase the vapour pressure of reaction products. ${ }^{7}$

It is interesting to compare these findings with results for the larger cyclic alkenes being examined in our previous work. For methyl-cyclohexene and methylene-cyclohexane $\left(\mathrm{C}_{7}\right.$-alkenes $)$ we found a drastic drop of mass yields below 100 mbar, for $\alpha$ - and $\beta$-pinene $\left(\mathrm{C}_{10}\right.$-alkenes $)$ below 50 mbar. This illustrates

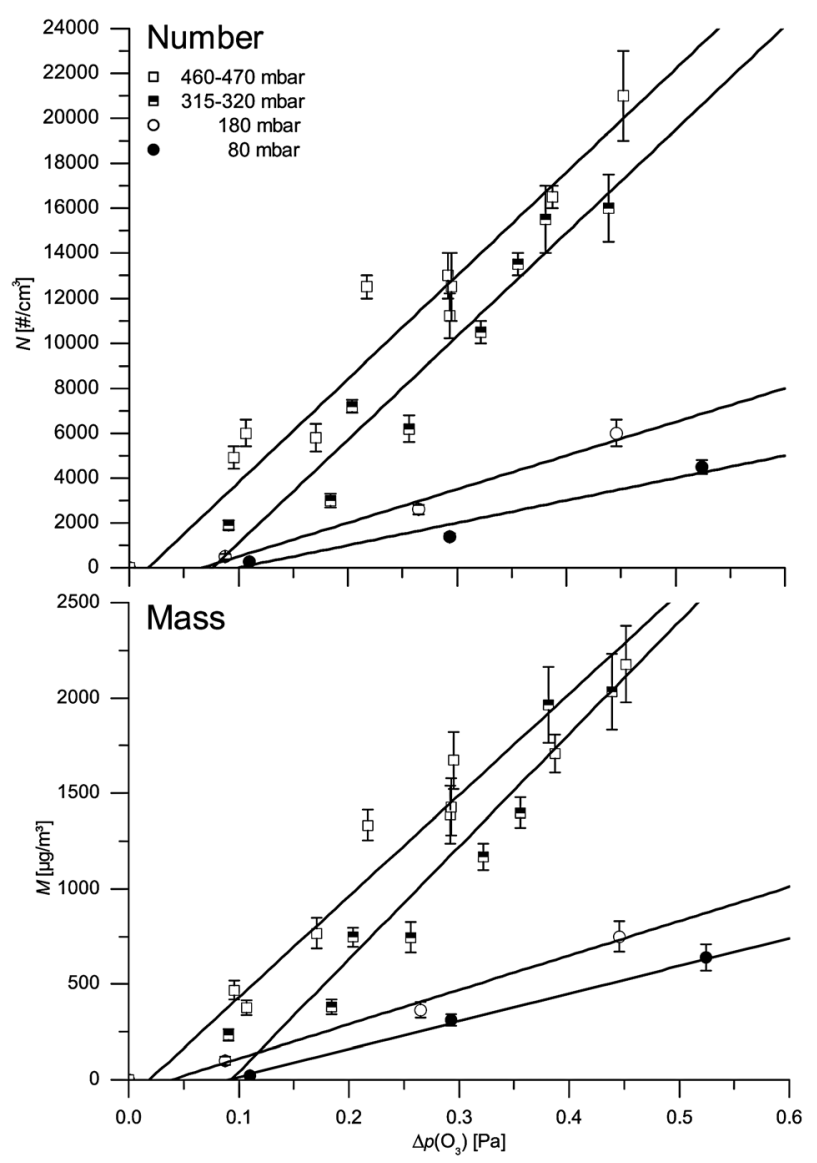

Fig. 7 Dependence of particle formation from ozone conversion at $465 \pm 5$ mbar, $318 \pm 3$ mbar, $180 \pm 2$ mbar and $80 \pm 2$ mbar. The values are those from the simulated particle size distribution. The straight lines result from linear regression. how increased heat capacities of $\mathrm{C}_{7}$ - and $\mathrm{C}_{10}$-alkenes dampen the effect of chemical activation compared to CHEX.

3.3.2 Presence of $\mathrm{SO}_{2}$. In the previous section we have discussed the low particle densities occurring during the CHEX ozonolysis. This observation led to the idea of producing additional particles from the parallel running formation of sulfuric acid. Sulfuric acid induced new particle formation was studied in detail in previous work, ${ }^{3,20,23}$ since it is a key process in atmospheric science. The recent measurements of Sipilä et al. showed a relation or "slope" of 1-2 for $\ln (J)-\ln \left(\left[\mathrm{H}_{2} \mathrm{SO}_{4}\right]\right)$ plots $(J$ is the nucleation rate) over a wide range of $\mathrm{H}_{2} \mathrm{SO}_{4}$ concentrations. ${ }^{3}$ These results were in agreement with atmospheric observations suggesting this slope to be between 1 and $2 .^{42,43}$ The much higher slopes in earlier studies (see ref. 3, 20, 23 and the literature cited therein) were explained as a result of ineffective growth of freshly formed particles to detectable sizes at low $\mathrm{H}_{2} \mathrm{SO}_{4}$ concentrations. The discussion in ref. 3 highlighted the critical influence of restricted residence times in flow reactor experiments and the improvements being achieved using new CPC designs that are capable of detecting particles down to a diameter of slightly above $1 \mathrm{~nm}$. The low particle number density produced during CHEX ozonolysis allows for a complementary experimental test of the sensitivity of sulfuric acid induced new particle formation. In our set-up the aerosol analysis is performed when the reaction is completed. Therefore all stable clusters initiating nucleation events have sufficient time for growing to detectable sizes. On the other hand it is clear that freshly formed clusters can coalesce or condense to existing particles in the course of reaction, which reduces observed particle numbers. This effect is inherent to the static reactor approach.

In Fig. 8 the influence of $\mathrm{SO}_{2}$ addition on the observed particle and aerosol mass formation is illustrated for experiments at 450 mbar. We chose the lower pressure instead of 1 bar because here the reaction mixture is prepared immediately after the expansion without further addition of bath gas. This procedure provided the best reproducibility of experiments. We observed a first increase in particle numbers and aerosol masses above a threshold of $2 \times 10^{-4} \mathrm{~Pa} \mathrm{SO}_{2}(2 \mathrm{ppb}$ at 1 bar). Above ca. $0.01 \mathrm{~Pa}(100 \mathrm{ppb}$ at 1 bar) the increase intensified. For $0.3 \mathrm{~Pa}$ ( $3 \mathrm{ppm}$ at 1 bar) 150000 particles per $\mathrm{cm}^{3}$ are observed compared to 5000 per $\mathrm{cm}^{3}$ in the absence of $\mathrm{SO}_{2}$. These observations illustrate how efficiently $\mathrm{H}_{2} \mathrm{SO}_{4}$ produces new particles when condensable organic material is abundant. For some $\mathrm{SO}_{2}$ concentrations we added water for testing the effect of humidity on the results. In these experiments the observed particle numbers and aerosol masses were significantly reduced at higher humidities except for the experiments at the lowest $\mathrm{SO}_{2}$ concentrations, where no clear trend was observed. This finding is similar to results of Bonn et al. for the $\alpha$-pinene ozonolysis. ${ }^{44}$

In order to compare our findings with the work of Sipilä et al. the $\mathrm{H}_{2} \mathrm{SO}_{4}$ concentrations being produced in the reaction sequence initiated by the $\mathrm{SO}_{2}+\mathrm{OH}$ reaction had to be calculated. In the simulation the rate coefficient from the present work for $\mathrm{CHEX}+\mathrm{O}_{3}$ and an $\mathrm{OH}$ yield of 0.5 was applied (see section 3.1 above). The simulation showed that under dry conditions (estimated mole fraction of water: $x\left(\mathrm{H}_{2} \mathrm{O}\right)>2 \mathrm{ppm}$ 


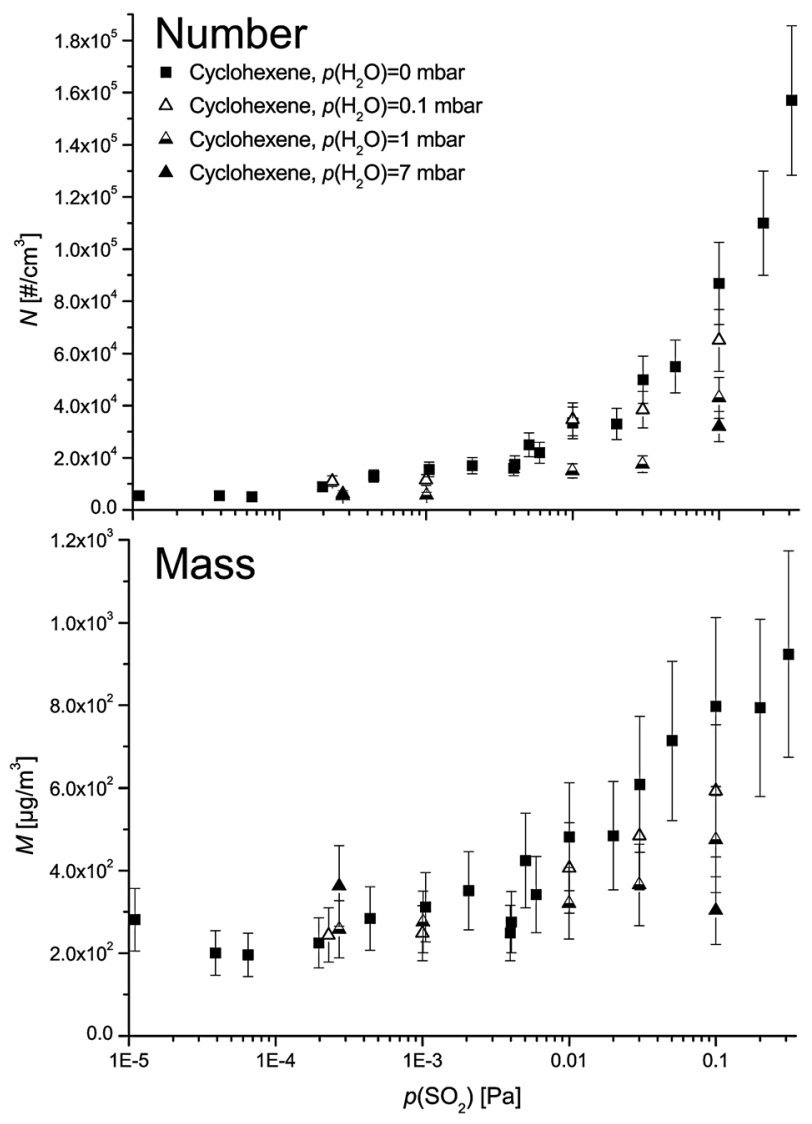

Fig. 8 Dependence of particle formation on the additon of $\mathrm{SO}_{2}$ to the initial gas mixture. The experiments were performed at $p_{\text {tot }}$ (synthetic air) $=450 \pm 10$ mbar under dry and in some cases humid conditions. Particle numbers and masses refer to simulated particle size distributions. $p_{0}\left(\mathrm{O}_{3}\right)=(0.085 \pm 0.015) \mathrm{Pa}, p_{0}(\mathrm{CHEX})=(1.28 \pm 0.05) \mathrm{Pa}$, and $T=(295 \pm 0.5) \mathrm{K}$.

from impurity of the used synthetic air and small leakages) $\mathrm{H}_{2} \mathrm{SO}_{4}$ was efficiently formed on the same time scale as the alkene was consumed. The predicted $\mathrm{H}_{2} \mathrm{SO}_{4}$ mole fraction profiles were largely independent on the water mole fraction in the gas mixture since the kinetic bottle neck is the $\mathrm{SO}_{2}+\mathrm{OH}$ reaction. Additional formation of $\mathrm{H}_{2} \mathrm{SO}_{4}$ from the reaction of stabilised CIs with $\mathrm{SO}_{2}$ was assumed to be negligible. This assumption is supported by recent work of Donahue et al. who reported the absence of stabilised CIs at 1 bar for CHEX ozonolysis. ${ }^{13}$ This is different for $\alpha$-pinene ozonolysis. Here Berndt et al. reported $26 \%$ of the $\mathrm{H}_{2} \mathrm{SO}_{4}$ to be formed via the $\mathrm{CI}$ channel. ${ }^{20}$ All kinetic simulations were performed with the DARS software package ${ }^{45}$ more details are given in the ESI. $\dagger$

In Fig. 9 our findings were tentatively compared with flow reactor experiments of Sipilä et al. using different CPCs. The static reactor results are plotted in terms of the additional number of particles being formed by $\mathrm{SO}_{2}$ addition as a function of the generated number density of $\mathrm{H}_{2} \mathrm{SO}_{4}$. For better comparison an offset of 1500 particles per $\mathrm{cm}^{3}$ is chosen. The main results of Sipila et al. are summarized by plotting the straight lines of Fig. 1 in their study representing measurements using different CPCs. We note here that caution is mandatory when comparing the different experiments. The issue of the CPC detection efficiency for small particles only

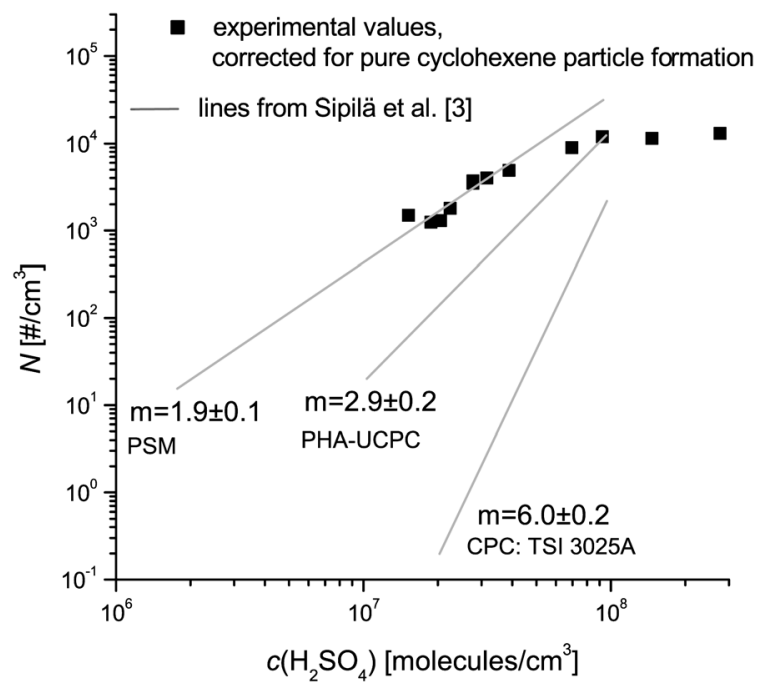

Fig. 9 Additional particle formation during CHEX ozonolysis in the presence of $\mathrm{SO}_{2}$ as a function of simulated $\mathrm{H}_{2} \mathrm{SO}_{4}$ number densities. $T=295 \mathrm{~K}, p_{\text {tot }}$ (synthetic air) $=450 \pm 10 \mathrm{mbar}$. The results are compared to slopes observed in flow reactor experiments using different CPCs. PHA-UCPC: Modified pulse height-analyzing ultrafine-condensation particle counter; PSM: Mixing type particle-size magnifier. More details are found in ref. 3.

applies to the flow reactor experiments. In the study of Sipilä et al. the ability of the mixing type particle-size magnifier (PSM) to lower the detection threshold down to sizes of around $1.5 \mathrm{~nm}$ was crucial for an efficient detection of all freshly formed particles. ${ }^{3}$ Only in the PSM experiments artefacts being related to CPC detection limits and limited residence times in flow reactors were efficiently suppressed. Our static reactor experiments are not sensitive to the applied CPC because we analyze the resulting particle numbers at the end of the reaction. Even in the presence of large amounts of $\mathrm{H}_{2} \mathrm{SO}_{4}$ the particle sizes are well above $20 \mathrm{~nm}$ (see Fig. 6), which is well above the detection limit of $4.5 \mathrm{~nm}$ of our TSI 3022 CPC.

The first important observation is that the onset of additional particle formation in the presence of $\mathrm{SO}_{2}$ is found at $\mathrm{H}_{2} \mathrm{SO}_{4}$ number densities, which produce particle numbers in the Leipzig flow reactor of the same order of magnitude as our background from CHEX ozonolysis. This similarity is only given for flow reactor experiments, where the mixing type particle-size magnifier is applied featuring the lowest particle detection limit. The second observation is the similar sensitivity of additional particle formation to $\mathrm{H}_{2} \mathrm{SO}_{4}$ concentrations in the static and flow reactor experiments in a $\mathrm{H}_{2} \mathrm{SO}_{4}$ concentration window above this threshold. The third finding is the flattening of increase of additional particle formation in our experiments at higher $\mathrm{H}_{2} \mathrm{SO}_{4}$ concentrations.

Considering the complementary character of the two experiments, namely.

- Controlled generation of $\mathrm{H}_{2} \mathrm{SO}_{4}$ and parallel running alkene ozonolysis for producing condensable species (flow reactor) vs. dominating alkene ozonolysis and parallel $\mathrm{H}_{2} \mathrm{SO}_{4}$ formation for generating condensation nuclei.

- Measurements of particle numbers at a fixed $\Delta t$ in the reactive flow for reducing particle loss via condensation and coagulation vs. characterisation of aerosol formation at the 
end of reaction allowing all initial nuclei contributing to either particle number or aerosol mass.

- $20-30 \%$ humidity in the flow reactor experiments $v$. dry conditions in the static reactor.

- Near-atmospheric conditions in the flow reactor vs. typical laboratory conditions at higher concentrations of reactants in the static reactor.

The similar sensitivity of new particle formation to $\mathrm{H}_{2} \mathrm{SO}_{4}$ concentrations between $1 \times 10^{7}$ and $4 \times 10^{7}$ molecules per $\mathrm{cm}^{3}$ is surprising.

Indeed, the dense vapour of semi-volatile oxidation products from CHEX ozonolysis seems to take over the role of the particle-size magnifier in the flow reactor experiments. The findings further suggest that the relation between new particle formation and $\mathrm{H}_{2} \mathrm{SO}_{4}$ concentrations is robust and can be observed in different gas mixtures. However, when the $\mathrm{H}_{2} \mathrm{SO}_{4}$ concentrations were increased the restrictions of the static reactor experiment became obvious. In Fig. 10 the experimental data of Fig. 8 for dry conditions are shown in a double logarithmic plot. The lower slopes at higher $\mathrm{H}_{2} \mathrm{SO}_{4}$ concentrations are marked. This effect was expected considering the loss of initial clusters to aerosol mass via condensation and coagulation. However, we think that curves as shown in Fig. 10 provide new types of experimental references for developing and refining models describing new particle formation and particle growth first in laboratory experiments. Interestingly, it shows a certain similarity with the relation of the logarithm of ignition delay times and the inverse temperature observed for the ignition of larger alkanes featuring the so called negative temperature coefficient (NTC) regime. ${ }^{27,46}$ Clearly, the chemical mechanisms leading to particle formation and controlling the dynamics of an ignition process have on first sight not very much in common. However, for both SOA formation and low temperature ignition the mechanistic branching in the peroxy radical chemistry is a key issue as recently discussed by Kroll and Seinfeld ${ }^{7}$ and Battin-Leclerc et al. ${ }^{47}$

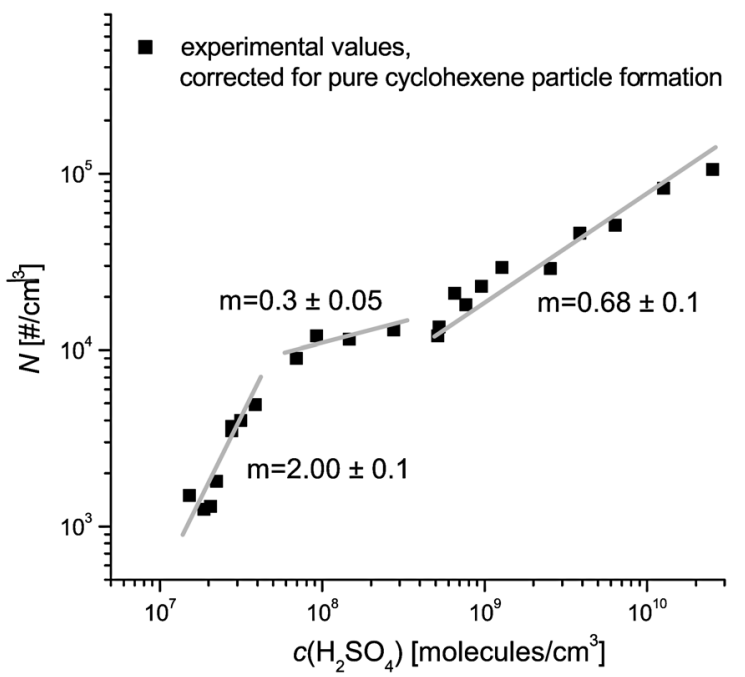

Fig. 10 Additional particle formation during CHEX ozonolysis in the presence of $\mathrm{SO}_{2}$ as a function of simulated $\mathrm{H}_{2} \mathrm{SO}_{4}$ number densities. $T=295 \mathrm{~K}, p_{\text {tot }}$ (synthetic air) $=450 \pm 10$ mbar. Slopes for three different regions of particle formation sensitivity are tentatively marked in the plot. in review articles. We note that the unraveling of the chemical mechanism explaining the NTC regime was the key for our present understanding of low temperature ignition and the complex reaction pathways of peroxy radicals being responsible for the NTC effect. The modeling of experiments as shown in Fig. 10 may help to gain a better understanding of organic-inorganic cross reactions being involved in SOA formation.

The strong pressure dependence of aerosol yields in the absence of $\mathrm{SO}_{2}$ being discussed in the previous section immediately raises the question to what extent this effect is carried through in the presence of $\mathrm{SO}_{2}$. In Fig. 11 the effect of pressure variation on aerosol formation during CHEX ozonolysis is shown in the presence of $\mathrm{H}_{2} \mathrm{SO}_{4}$. The first observation is that for pressure above 80 mbar a significant enhancement of particle and mass yields is found. This is especially true for the highest $\mathrm{SO}_{2}$ concentrations. The drastic drop of aerosol yields between 320 and 180 mbar (see Fig. 7) is not observed when $\mathrm{H}_{2} \mathrm{SO}_{4}$ controls the formation of condensation nuclei. However, at $40 \mathrm{mbar}$ aerosol formation breaks down even in the presence of high $\mathrm{H}_{2} \mathrm{SO}_{4}$ number densities. Before further conclusions can be drawn the pressure dependence of $\mathrm{H}_{2} \mathrm{SO}_{4}$ formation must be considered. Here the initial step $\mathrm{SO}_{2}+\mathrm{OH} \rightarrow \mathrm{HOSO}_{2}$ is rate limiting and is known to be pressure dependent. ${ }^{48}$ However, the absolute rate is expected to drop by a factor of 3 between 450 and 30 mbar while the

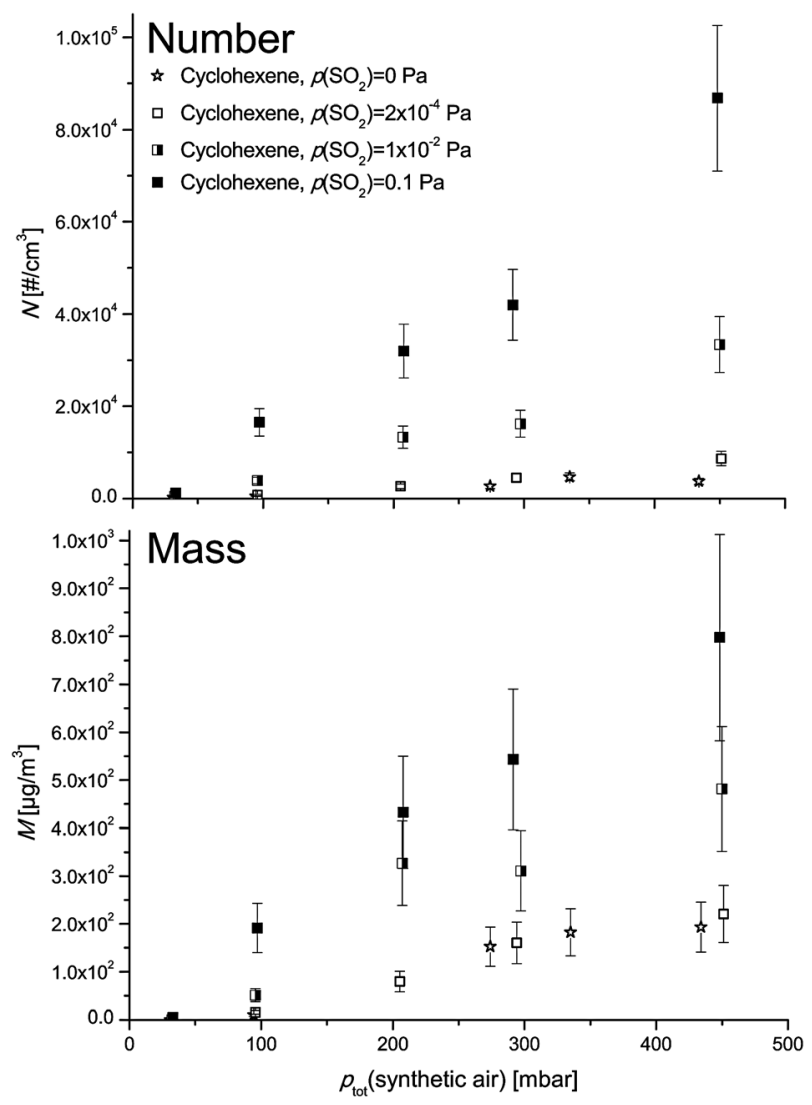

Fig. 11 Pressure dependence of enhanced particle formation upon $\mathrm{SO}_{2}$ addition for $p_{\text {tot }}$ (synthetic air) $=40-450 \pm 10 \mathrm{mbar}, p_{0}\left(\mathrm{O}_{3}\right)=$ $0.085 \pm 0.015 \mathrm{~Pa}, p_{0}(\mathrm{CHEX})=1.28 \pm 0.05 \mathrm{~Pa}$, and $T=(295 \pm 0.5) \mathrm{K}$. The values refer to simulated particle size distributions. 
$\mathrm{SO}_{2}$ concentrations are changed by orders of magnitude. Thus the pressure dependence of $\mathrm{H}_{2} \mathrm{SO}_{4}$ formation cannot explain the absence of particle formation at 40 mbar but may be responsible for the minor changes in particle yields observed between 200 and 450 mbar.

Therefore we have clear indications that the stabilisation of initial clusters containing $\mathrm{H}_{2} \mathrm{SO}_{4}$ does not work at low pressures around $40 \mathrm{mbar}$. The reason is probably that the clusters become simply too warm due to the exothermicity of the interaction of $\mathrm{H}_{2} \mathrm{SO}_{4}$ with organic compounds. Another explanation might be the absence of condensable vapours at low pressures. For testing these hypotheses we analysed the effect of $\mathrm{SO}_{2}$ addition during the ozonolysis of $\alpha$-pinene, where a significant drop of aerosol yields was observed for pressures below 40 mbar. ${ }^{12}$ Here condensable vapours are definitely abundant around 40 mbar. The results of these experiments are shown in Fig. 12. First we see the invariance of aerosol masses between 100-1000 mbar and particle numbers between 200-1000 mbar in the absence of $\mathrm{SO}_{2}$. This finding illustrates that a high pressure limit with regard to aerosol yields is achieved for the $\mathrm{C}_{10}$-alkene $\alpha$-pinene above 100-200 mbar. Similar to the CHEX ozonolysis the effect of $\mathrm{SO}_{2}$ addition at 40 mbar on aerosol yields in terms of number and mass is negligible. For experiments around 90 mbar an enhancement of aerosol yields cannot really be stated for $\alpha$-pinene, which is different to CHEX. At higher pressures we also see a
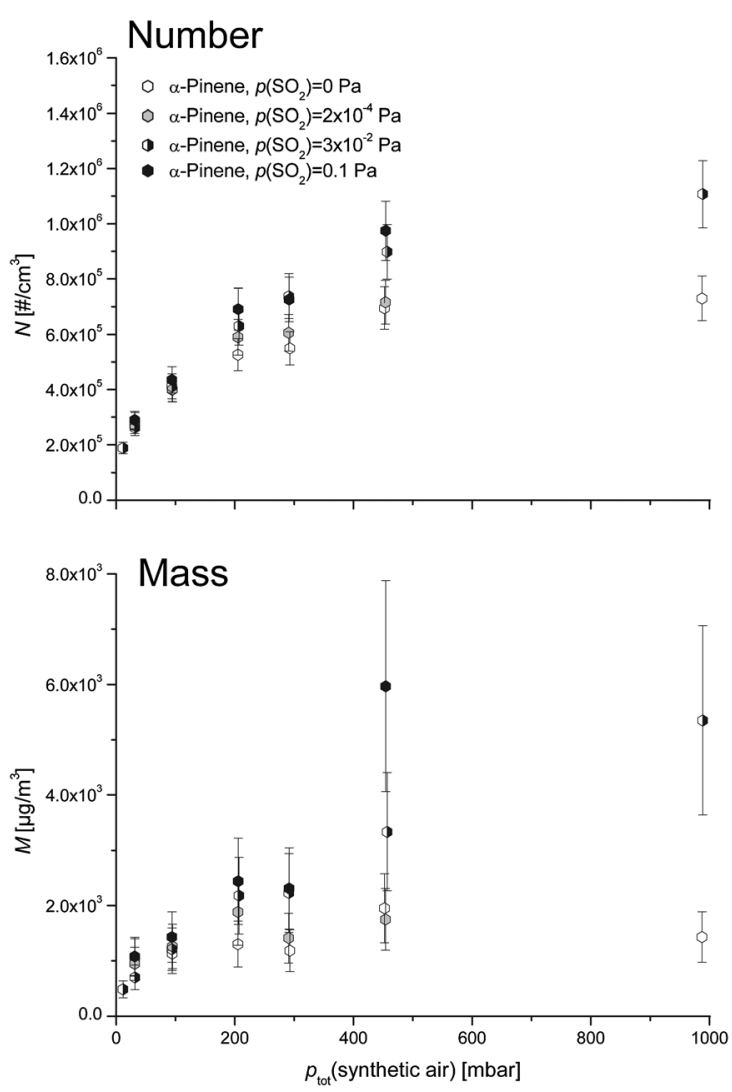

Fig. 12 Pressure dependence of enhanced particle formation during $\alpha$-pinene ozonolysis upon $\mathrm{SO}_{2}$ addition. $p_{\text {tot }}$ (synthetic air) $=30-450 \pm$ $10 \mathrm{mbar}, p_{0}\left(\mathrm{O}_{3}\right)=0.045 \pm 0.01 \mathrm{~Pa}, p_{0}(\alpha$-pinene $)=2.5 \pm 0.05 \mathrm{~Pa}$, and $T=(295 \pm 0.5) \mathrm{K}$. significant increase in particle numbers and aerosol masses when $\mathrm{SO}_{2}$ is added. Since high particle numbers were observed in the absence of $\mathrm{SO}_{2}$ the enhancement by $\mathrm{SO}_{2}$ addition is limited. The absence of the enhancement of particle formation at 40 mbar also for $\alpha$-pinene points to the exothermicity of initial cluster formation as the underlying effect. At the same time the pressure dependence of aerosol yields is clearly not identical for $\alpha$-pinene and CHEX ozonolysis for both the presence and absence of $\mathrm{SO}_{2}$. These observations might indicate that alkene specific cross reactions of $\mathrm{H}_{2} \mathrm{SO}_{4}$ with oxidation products have to be considered.

Clearly, much more efforts have to be made in future for getting a more detailed picture of organic-inorganic cross reactions being relevant for SOA formation in the atmosphere. The observations of this study illustrate that a detailed knowledge of the stabilisation of initial clusters is needed for unravelling the complex mechanisms leading to aerosol formation. Collisional stabilisation as well as the inter- and intramolecular vibrational relaxation have to be taken into account.

\section{Conclusions}

We have performed a detailed analysis of the pressure dependence of reaction product and SOA formation during the gasphase ozonolysis of cyclohexene. The results showed a largely suppressed particle formation below 300 mbar which coincided with an enhanced formation of ethene. This finding confirmed previously suggested reaction pathways explaining the enhanced formation of $\mathrm{CO}$, ethene and ketene at low pressures during the ozonolysis of methyl-cyclohexene and $\alpha$-pinene. ${ }^{12}$ The results underline the important role of mechanistic branching in the vinylhydroperoxide channel for SOA formation being discussed in the same preceding work and previous studies. ${ }^{7}$ The analysis of decomposition reactions via $\mathrm{C}-\mathrm{C}$-fission at low pressures can reveal crucial features of the potential energy surface (PES) determining the available reaction pathways in the complex intermediate chemistry leading to SOA formation. By "flooding" the PES with excess energy at low pressures, the dynamics of the chemical activation driven chemistry beyond the vinylhydroperoxide stage can be observed.

The low particle number densities being generated during CHEX ozonolysis allowed for an analysis of the sensitivity of the presence of $\mathrm{H}_{2} \mathrm{SO}_{4}$ in the gas mixture to new particle formation. Near the critical $\mathrm{H}_{2} \mathrm{SO}_{4}$ number density, where additional particle formation can be first observed, a similar sensitivity to recent near-atmospheric flow reactor experiments and atmospheric conditions is found. ${ }^{3}$ At higher $\mathrm{H}_{2} \mathrm{SO}_{4}$ concentrations the sensitivity is lower due to an increased loss of initial clusters by coagulation and condensation. At pressures below 50 mbar particle formation is suppressed even for very high $\mathrm{H}_{2} \mathrm{SO}_{4}$ number densities.

In general, the strong and gas mixture specific pressure effects on aerosol yields in our laboratory experiments suggest that a critical analysis of pressure effects on atmospheric aerosol formation processes seems appropriate when they occur at pressures different from 1 bar. Geo-engineering strategies based on stratospheric sulfur injection ${ }^{49}$ and atmospheric aerosol formation on $\operatorname{Titan}^{50}$ are two examples. However, such an 
analysis is beyond the scope of this work and at this stage it is clearly improper to simply extrapolate the laboratory results.

\section{Acknowledgements}

The continous support of this work by Prof. Martin Suhm and Prof. Karlheinz Hoyermann is gratefully acknowledged. We thank the DFG (GRK 782) and the Fonds der Chemischen Industrie for funding. We thank Dr. Torsten Berndt and Prof. Boris Bonn for their helpful comments and discussions about the pressure dependence of sulfuric acid induced new particle formation.

\section{References}

1 V. Ramanathan, P. Crutzen, J. Kiehl and D. Rosenfeld, Science, 2001, 294, 2119-2124.

2 M. Sekiguchi, T. Nakajima, K. Suzuki, K. Kawamoto, A. Higurashi, D. Rosenfeld, I. Sano and M. Sonoyo, J. Geophys. Res., 2003, 109, JD003359.

3 M. Sipilä, T. Berndt, T. Petäjä, D. Brus, J. Vanhanen, F. Stratmann, J. Patokoski, R. L. Mauldin, A.-P. Hyvärinen, H. Lihavainen and M. Kulmala, Science, 2010, 327, 1243-1246.

4 J. Kirkby, J. Curtius, J. Almeida, E. Dunne, J. Duplissy, S. Ehrhart, A. Franchin, S. Gagne, L. Ickes, A. Kurten, A. Kupc, A. Metzger, F. Riccobono, L. Rondo, S. Schobesberger, G. Tsagkogeorgas, D. Wimmer, A. Amorim, F. Bianchi, M. Breitenlechner, A. David, A. Dommen, J. Downard, M. Ehn, R. C. Flagan, S. Haider, A. Hansel, D. Hauser, W. Jud, H. Junninen, F. Kreissl, A. Kvashin, A. Laaksonen, K. Lehtipalo, J. Lima, E. R. Lovejoy, V. Makhmutov, S. Mathot, J. Mikkila, P. Minginette, S. Mogo, T. Nieminen, A. Onnela, P. Pereira, T. Petaja, R. Schnitzhofer, J. H. Seinfeld, M. Sipila, Y. Stozhkov, F. Stratmann, A. Tome, J. Vanhanen, Y. Viisanen, A. Vrtala, P. E. Wagner, H. Walther, E. Weingartner, H. Wex, P. Winkler, K. S. Carslaw, D. R. Worsnop, U. Baltensperger and M. Kulmala, Nature, 2011, 476, 429-433.

5 N. M. Donahue, E. R. Trump, J. R. Pierce and I. Riipinen, Geophys. Res. Lett., 2011, 38, L16801.

6 T. Petäjä, M. Sipilä, P. Paasonen, T. Nieminen, T. Kurtén, I. K. Ortega, F. Stratmann, H. Vehkamäki, T. Berndt and M. Kulmala, Phys. Rev. Lett., 2011, 106, 228302.

7 J. H. Kroll and J. H. Seinfeld, Atmos. Environ., 2008, 42, 3593-3624.

8 B. Bonn, H. Korhonen, T. Petäjä, M. Boy and M. Kulmala, Atmos. Chem. Phys. Discuss., 2007, 7, 3901-3939.

9 D. Johnson and G. Marston, Chem. Soc. Rev., 2008, 37, 699-716.

10 M. Hallquist, J. C. Wenger, U. Baltensperger, Y. Rudich, D. Simpson, M. Claeys, J. Dommen, N. M. Donahue, C. George, A. H. Goldstein, J. F. Hamilton, H. Herrmann, T. Hoffmann, Y. Iinuma, M. Jang, M. E. Jenkin, J. L. Jimenez, A. KiendlerScharr, W. Maenhaut, G. McFiggans, T. F. Mentel, A. Monod, A. S. H. Prévot, J. H. Seinfeld, J. D. Surratt, R. Szmigielski and J. Wildt, Atmos. Chem. Phys., 2009, 9, 5155-5236.

11 J. L. Wolf, M. A. Suhm and T. Zeuch, Angew. Chem., Int. Ed., 2009, 48, 2231-2235.

12 J. L. Wolf, S. Richters, J. Pecher and T. Zeuch, Phys. Chem. Chem. Phys., 2011, 13, 10952-10964.

13 N. M. Donahue, G. T. Drozd, S. A. Epstein, A. A. Presto and J. H. Kroll, Phys. Chem. Chem. Phys., 2011, 13, 10848-10857.

14 S. Hatakeyama, T. Tanonaka, J.-h. Weng, H. Bandow, H. Takagi and H. Akimoto, Environ. Sci. Technol., 1985, 19, 935-942.

15 R. Atkinson, E. C. Tuazon and S. M. Aschmann, Environ. Sci. Technol., 1995, 29, 1860-1866.

16 M. Kalberer, J. Yu, D. R. Cocker, R. C. Flagan and J. H. Seinfeld, Environ. Sci. Technol., 2000, 34, 4894-4901.

17 S. M. Aschmann, E. C. Tuazon, J. Arey and R. Atkinson, J. Phys. Chem. A, 2003, 107, 2247-2255.

18 M. D. Keywood, V. Varutbangkul, R. Bahreini, R. C. Flagan and J. H. Seinfeld, Environ. Sci. Technol., 2004, 38, 4157-4164.
19 L. Müller, M. C. Reinnig, J. Warnke and Th. Hoffmann, Atmos. Chem. Phys., 2008, 8, 1423-1433.

20 T. Berndt, O. Böge and F. Stratmann, Atmos. Environ., 2004, 38, 2145-2153.

21 J. H. Kroll, J. S. Clarke, N. M. Donahue, J. G. Anderson and K. L. Demerjian, J. Phys. Chem. A, 2001, 105, 1554-1560.

22 J. H. Kroll, N. M. Donahue, V. J. Cee, K. L. Demerjian and J. G. Anderson, J. Am. Chem. Soc., 2002, 124, 8518-8519.

23 T. Berndt, O. Böge, J. Heintzenberg and M. Kulmala, Science, 2005, 307, 698-700.

24 K. J. Heaton, M. A. Dreyfus, S. Wang and M. V. Johnston, Environ. Sci. Technol., 2007, 41, 6129-6136.

25 W. Hack, K. Hoyermann, M. Olzmann, B. Viscolcz, J. Wehmeyer and T. Zeuch, Proc. Combust. Inst., 2005, 30, 1005-1013.

26 K. Hoyermann, J. Nothdurft, M. Olzmann, J. Wehmeyer and T. Zeuch, J. Phys. Chem. A, 2006, 110, 3165-3173.

27 T. Zeuch, G. Moreac, S. S. Ahmed and F. Mauss, Proc. Combust. Inst., 2008, 155, 651-674.

28 A. R. Rickard, D. Johnson, C. D. McGill and G. Marston, J. Phys. Chem. A, 1999, 103, 7656-7664.

29 P. Neeb and G. K. Moortgat, J. Phys. Chem. A, 1999, 103, 9003-9012.

30 J. D. Fenske, K. T. Kuwata, K. N. Houk and S. E. Paulson, J. Phys. Chem. A, 2000, 104, 7246-7254.

31 J. H. Kroll, S. R. Sahay, J. G. Anderson, K. L. Demerjian and N. M. Donahue, J. Phys. Chem. A, 2001, 105, 4446-4457.

32 M. D. Keywood, J. H. Kroll, V. Varutbangkul, R. Bahreini, R. C. Flagan and J. H. Seinfeld, Environ. Sci. Technol., 2004, 38, $3343-3350$.

33 K. M. Henry and N. M. Donahue, Environ. Sci. Technol., 2011, 45, 696-700.

34 J. Treacy, M. Curley, J. Wenger and H. Sidebottom, J. Chem. Soc., Faraday Trans., 1997, 93, 2877-2881.

35 R. Atkinson and J. Arey, Chem. Rev., 2003, 103, 4605-4638.

36 R. D. Cusick and R. Atkinson, Int. J. Chem. Kinet., 2005, 37, 183-190.

37 T. L. Malkin, A. Goddard, D. E. Heard and P. W. Seakins, Atmos. Chem. Phys., 2010, 10, 1441-1459.

38 K. Hoyermann, S. Maarfeld, F. Nacke, J. Nothdurft, M. Olzmann, J. Wehmeyer, O. Welz and T. Zeuch, Phys. Chem. Chem. Phys., 2010, 12, 8953-8967.

39 H. Niki, P. D. Maker, C. M. Savage and L. P. Breitenbach, Environ. Sci. Technol., 1983, 17, 312A-322A.

40 J. H. Kroll and J. H. Seinfeld, Environ. Sci. Technol., 2005, 39, 4159-4165.

41 A. Sadezky, R. Winterhalter, B. Kanawati, A. Römpp, B. Spengler, A. Mellouki, G. Le Bras, P. Chaimboult and G. K. Moortgat, Atmos. Chem. Phys., 2008, 8, 2667-2699.

42 S.-L. Sihto, M. Kulmala, V.-M. Kerminen, M. D. Maso, T. Petäjä, I. Riipinen, H. Korhonen, F. Arnold, R. Janson, M. Boy, A. Laaksonen and K. E. J. Lehtinen, Atmos. Chem. Phys., 2006, 6, 4079-4091.

43 I. Riipinen, S.-L. Sihto, M. K. F. Arnold, M. D. Maso, W. Birmili, K. Saarnio, K. Teinilä, V.-M. Kerminen, A. Laaksonen and K. E. J. Lehtinen, Atmos. Chem. Phys., 2007, 7, 1899-1914.

44 B. Bonn, G. Schuster and G. K. Moortgat, J. Phys. Chem. A, 2002, 106, 2869-2881.

45 "Digital Analysis of Reactive Systems (DARS)", http://loge.se/ Products/DARS-Basics.html, 2012.

46 F. Battin-Leclerc, O. Herbinet, P.-A. Glaude, R. Fournet, Z. Zhou, L. Deng, H. Guo, M. Xie and F. Qi, Angew. Chem., Int. Ed., 2010, 49, 3169-3172.

47 F. Battin-Leclerc, E. Blurock, R. Bounaceur, R. Fournet, P.-A. Glaude, O. Herbinet, B. Sirjean and V. Warth, Chem. Soc. Rev., 2011, 40, 4762-4782.

48 H. Somnitz, Phys. Chem. Chem. Phys., 2004, 6, 3844-3851.

49 V. Brovkin, V. Petoukhov, M. Claussen, E. Bauer, D. Archer and C. Jaeger, Clim. Change, 2009, 92, 243-259.

50 G. Israel, C. Szopa, F. Raulin, M. Cabane, H. B. Niemann, S. K. Atreya, S. J. Bauer, J.-F. Brun, E. Chassefière, E. C. P. Coll, D. Coscia, A. Hauchecorne, P. Millian, M.-J. Nguyen, T. Owen, W. Riedler, R. E. Samuelson, J.-M. Siguier, M. Steller, R. Sternberg and C. Vidal-Madjar, Nature, 2005, 438, 796-799.

51 O. Welz, J. D. Savee, D. L. Osborn, S. S. Vasu, C. J. Parcival, D. E. Shallcross and C. A. Taatjes, Science, 2012, 335, 204-207. 